\title{
Corrosion Resistance Enhancement of SAE 1020 Steel after Chromium Implantation by Nitrogen Ion Recoil
}

\author{
Geraldo Francisco Gomes ${ }^{\mathrm{a} *}$, Mario Ueda ${ }^{\mathrm{b}}$, Antonio Fernando Beloto ${ }^{\mathrm{c}}$, \\ Roberto Zenhei Nakazato ${ }^{\mathrm{d}}$,Helfried Reuther ${ }^{\mathrm{e}}$ \\ ${ }^{a}$ Science and Technology Analyst, Laboratório de Combustão e Propulsão - LCP, \\ Instituto Nacional de Pesquisas Espaciais, LCP - INPE, \\ Rodovia Pres. Dutra, km 40, 12630-000 Cachoeira Paulista - SP, Brazil \\ ${ }^{\mathrm{b}}$ Laboratório Associado de Plasma - LAP/INPE, Brazil \\ ${ }^{\circ}$ Laboratório Associado de Sensores e Materiais - LAS/INPE, Brazil \\ ${ }^{\mathrm{d} D e p t o . ~ d e ~ F i ́ s i c a ~ e ~ Q u i ́ m i c a, ~ U N E S P / F E G, ~ G u a r a t i n g u e t a ́ ~-~ S P, ~ B r a z i l ~}$ \\ ${ }^{\mathrm{e}}$ Forschungszentrum Rossendorf, FZR, Dresden, Germany
}

Received: July 19, 2004; Revised: October 10, 2005

\begin{abstract}
SAE 1020 construction steel is widely used as mortar reinforcement and small machine parts, but aside good surface properties as high ductility, hardness and wear resistance, its surface is prone to severe corrosion. As it is known, Chromium in amount over $12 \%-13 \%$ in the Fe alloys renders them resistance to several corrosive attacks. SAE 1020 samples were recovered with Chromium film and then bombarded either by nitrogen Ion Beam (IB) or Plasma Immersion Ion Implantation (PIII) to recoil implant $\mathrm{Cr}$ atoms in the Fe matrix. Samples treated by $100 \mathrm{keV} \mathrm{N}^{+} \mathrm{IB}$ showed irregular, thin $\mathrm{Cr}$ profile, remaining a part of the film on the surface, to about $10 \mathrm{~nm}$. Samples treated by $40 \mathrm{kV}$ N PIII presented Cr layer of about $18 \%$ at., ranging to around $90 \mathrm{~nm}$. Cr of the film was implanted in the Fe matrix in an almost flat profile. Results of corrosion test showed good performance of the PIII treated sample. The IB treated sample showed some enhancement over the non-treated reference and the only Cr film deposited sample showed no modification on the corrosion behavior as compared to the non-treated reference sample.
\end{abstract}

Keywords: corrosion, plasma immersion ion implantation, SAE 1020

\section{Introduction}

SAE 1020 construction steel (SAE/AISI 1020 grade) is most used as concrete reinforcement and small machine parts $^{1-3}$. But aside good surface properties as ductility, hardness and wear resistance, it is prone to severe corrosion. As the presence of Chromium (Cr), in excess of $12 \%-13 \%$ in $\mathrm{Fe}$ alloys, turns them resistant to several corrosive attacks, we tried to introduce $\mathrm{Cr}$ into the surface of this steel in such amounts. $\mathrm{Cr}$ films were deposited by electron beam on SAE 1020 surface and then bombarding either by nitrogen Plasma Immersion Ion Implantation (PIII) or ion beam (IB), $\mathrm{Cr}$ atoms are recoil introduced into the steel matrix ${ }^{4,5}$.

Numerical simulations were performed using 2000.40 version of SRIM ${ }^{6}$ code, Stop and Range of Ions in Matter, from J.F. Ziegler and J.P. Biersack, of IBM Co., that showed the range of $\mathrm{Cr}$ and $\mathrm{N}$ atoms in $\mathrm{Cr} / \mathrm{Fe}$ region, where the presence of $\mathrm{Cr}$ film was taken into account. Simulations showed that $\mathrm{Cr}$ atoms can be introduced in the steel surface by nitrogen ion recoil. Corrosion analysis was performed to compare the treated sample behavior with that of the non-treated reference sample?

\section{Experimental}

SAE 1020 steel samples were polished to $1 \mu \mathrm{m}$ with alumina powder and covered with $\mathrm{Cr}$ film of several thicknesses, Figure 1, in a $5 \mathrm{keV}$ electron beam device prior to ion bombardment. Ion bombardment was performed using a $100 \mathrm{keV} \mathrm{N}^{+}$beam to doses of $2 \times 10^{17} \mathrm{~N} / \mathrm{cm}^{2}$ and $5 \times 10^{17} \mathrm{~N} / \mathrm{cm}^{2}$. In the case of nitrogen Plasma Immersion Ion Implantation, PIII, samples were bombarded using high voltage pulses at $40 \mathrm{kV}$ and $8 \times 10^{-2}$ mbar in a nitrogen plasma, to doses around $5 \times 10^{17} \mathrm{~N} / \mathrm{cm}^{2}$.
SRIM simulation showed $\mathrm{Cr}$ atoms introduced into steel surface after $\mathrm{N}$ recoil, at several ion energies. For the AES (Auger Electron Spectroscopy) measurements applied for determination of the elemental concentration in the samples, a spectrometer from FISONS Instruments Surface Science, model MICROLAB 310-F was used. Corrosion properties were measured in a PAR-EG\&G 283 apparatus, using saline $\mathrm{NaCl}$ at $0.66 \mathrm{M}, \mathrm{pH} 6.0$, aerated solution, RT SCE, $\mathrm{KCl}$ saturated, $0.333 \mathrm{mVs}^{-1}$ polarization.

\section{Results}

The SRIM simulation, of nitrogen ion bombardment on $\mathrm{Cr}$ film, showing $\mathrm{Cr}$ range into the iron matrix, as can be seen in the Figure 2, were confirmed by AES results. Figure 3 presents AES profile of samples treated by nitrogen ion beam at $100 \mathrm{keV}$ energy. It seems to be large enough to make the $\mathrm{N}^{+}$cross the $\mathrm{Cr}$ film, and despite of a $30 \%$ $\mathrm{Cr}$ content measured in the region just beneath the interface between the $\mathrm{Cr}$ film and the steel, $\mathrm{Cr}$ atoms lie in a very thin layer, less than $9 \mathrm{~nm}$. The best $\mathrm{Cr}$ implantation was attained using $\mathrm{Cr}$ film of $50 \mathrm{~nm}$ and PIII at $40 \mathrm{kV}$, with percentages over $13 \% \mathrm{Cr}$ at the surface in a layer ranging for more than $90 \mathrm{~nm}$, Figure 4. Oxygen appears like impurities in the modified layer, coming from the pumping system.

Corrosion tests indicated remarkable increase in SAE 1020 resistance under corrosive medium attack, even in the case of IB, that produced a modest $\mathrm{Cr}$ enriched layer in treated samples, where a great amount of the $\mathrm{Cr}$ remains in the original film, as can be seen in Figure 5. For IB treated samples, there is a gain in the current density, which was the smallest result. For PIII treated samples, there is a gain in the corrosion potential, towards a more noble potential. For 


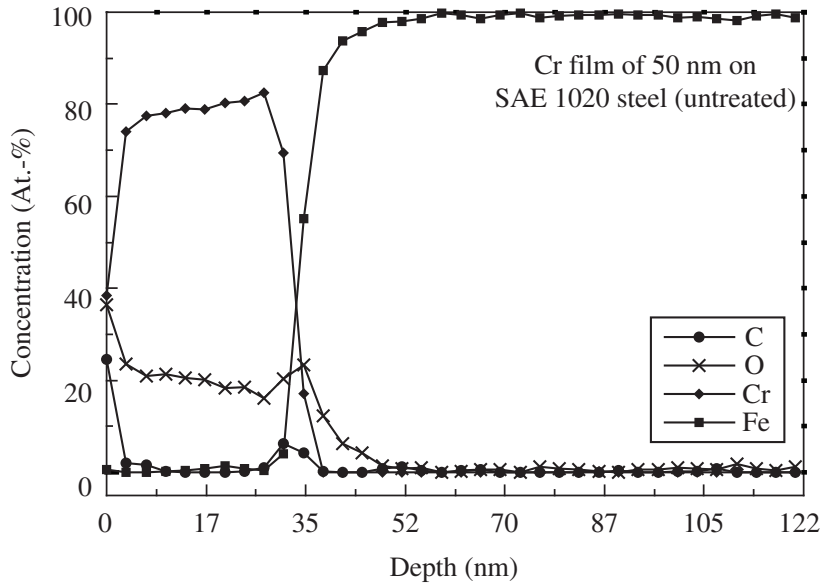

Figure 1. AES profile of a $50 \mathrm{~nm}$ Cr film on SAE 1020, deposited by a $5 \mathrm{keV}$ electron beam.

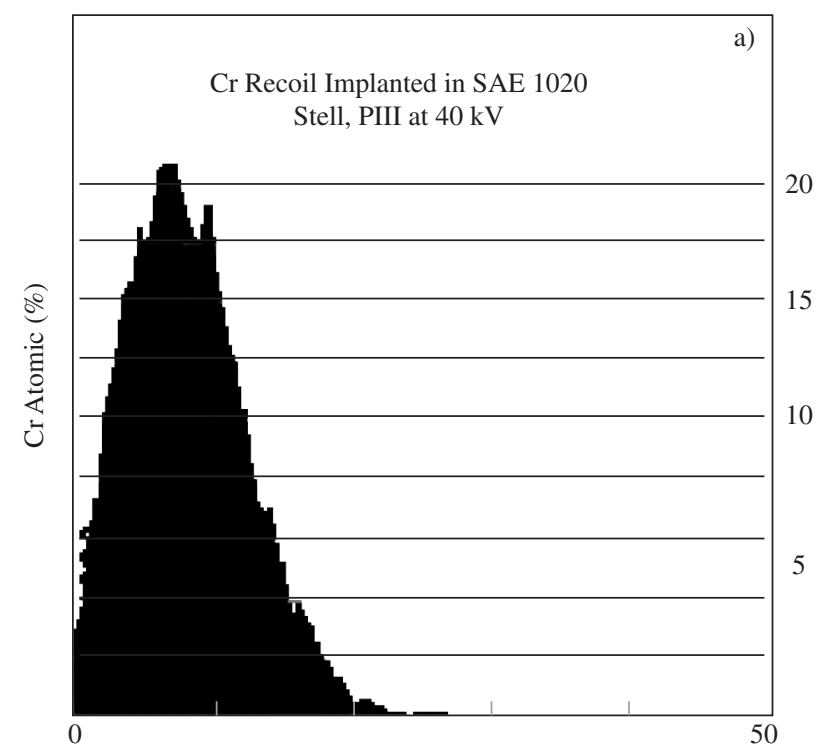

Depth Profile (nm) comparison purposes, Figure 6 depicts the corrosion profile of SAE 304 stainless steel under the same corrosion environment.

\section{Conclusion}

The computer simulations showed that a $\mathrm{Cr}$ film on the surface of mild steel, if bombarded with energetic nitrogen ions, can implant some $\mathrm{Cr}$ atoms by recoil process.

Thus, to produce a Cr-rich layer on the surface of mild steel, aiming to enhance its corrosion resistance, we deposited $\mathrm{Cr}$ films of several thicknesses on SAE 1020 steel surface. Then, we proceed to bombardment of the films, either by Nitrogen PIII, at $40 \mathrm{kV}$ or by IB, at $100 \mathrm{keV}$.

Experimental results showed that $\mathrm{Cr}$ atoms penetrated deeply in the iron matrix, beyond the theoretical ranges. IB implantation presented an irregular profile, with a maximum of $30 \%$ at., going into the surface for only about $10 \mathrm{~nm}$, with a large part of the original film remaining on the steel surface. In the case of PIII, the modified layer showed good uniformity, with a maximum of $17 \%$ at., ranging

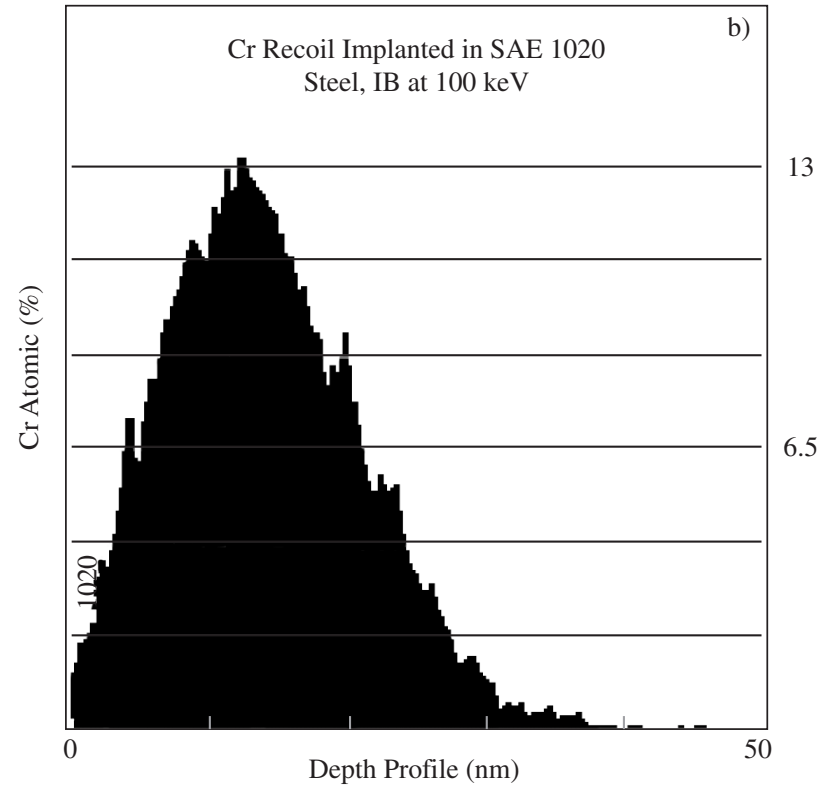

Figure 2. Theoretical depth profile of $\mathrm{Cr}$ atoms in SAE 1020, after Nitrogen recoil, a) at $40 \mathrm{kV}$ (PIII); and b) $100 \mathrm{keV}$ (IB), beyond the $50 \mathrm{~nm}$ original $\mathrm{Cr}$ film.

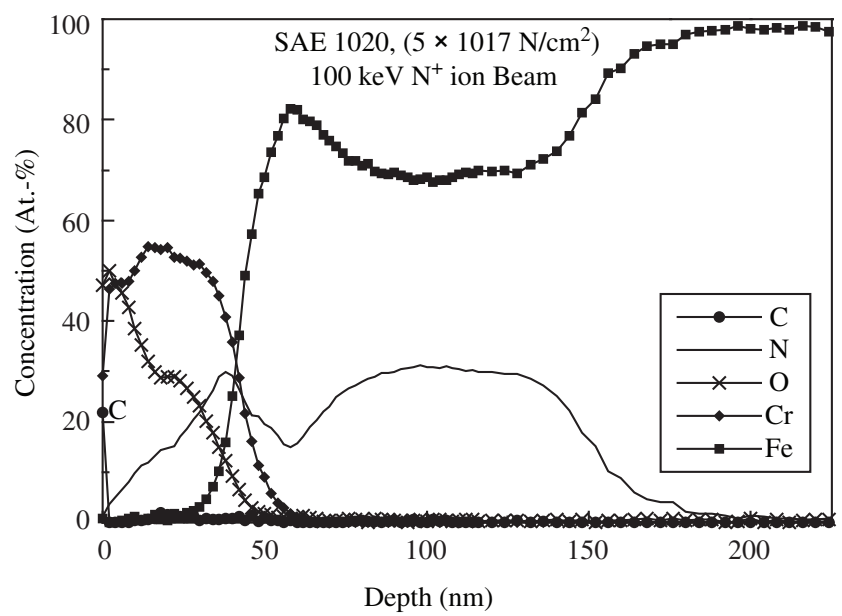

Figure 3. AES depth profile of Cr into SAE 1020 matrix, after IB bombardment by $\mathrm{N}+$ at $100 \mathrm{keV}$ energy.

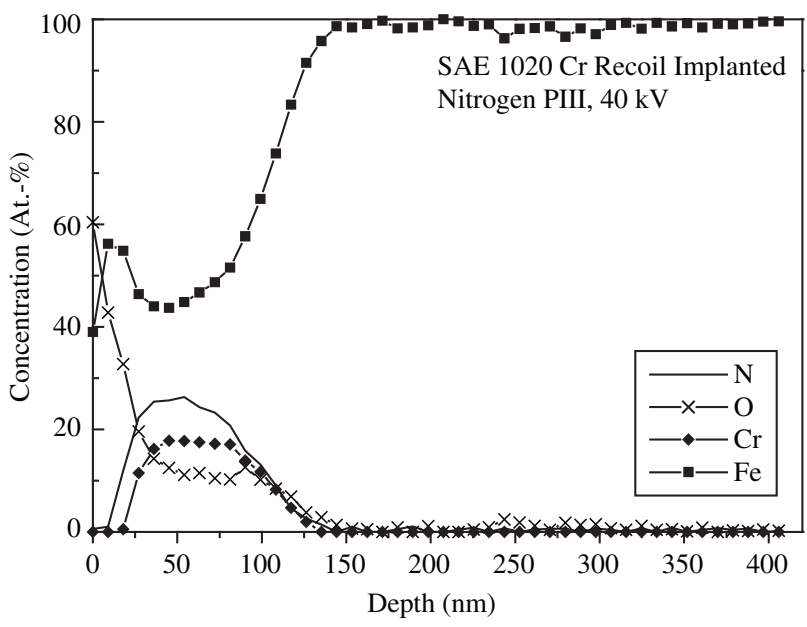

Figure 4. AES depth profile of the Cr into SAE 1020 matrix, after N PIII bombardment at $40 \mathrm{kV}$. 


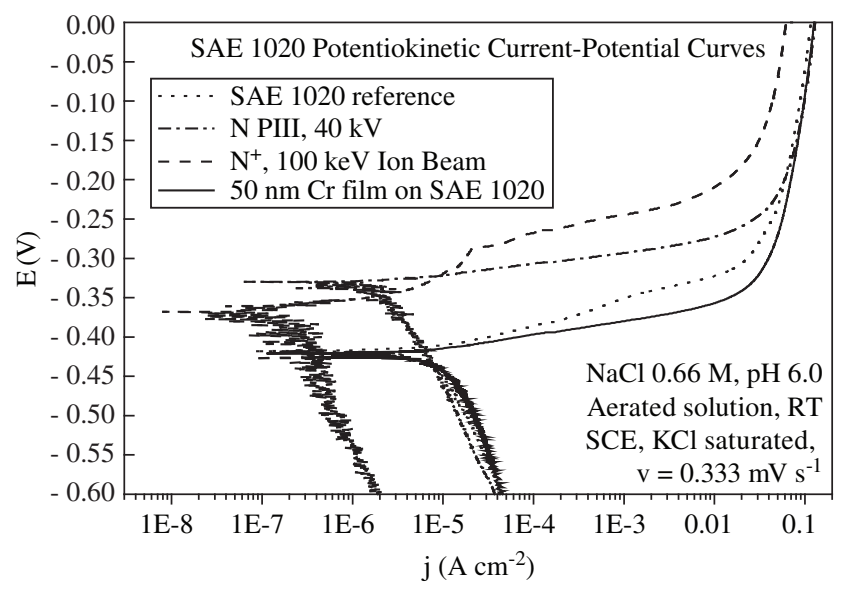

Figure 5. Corrosion profile of SAE 1020 steel after several treatment.

to about $90 \mathrm{~nm}$, in an almost Gaussian profile, following the nitrogen profile. All the $\mathrm{Cr}$ atoms from the film were implanted in the steel surface, except those lost by sputtering.

Corrosion test showed good performance of the PIII treated sample. The IB treated sample showed some enhancement over the non-treated reference and the only $\mathrm{Cr}$ film treated sample showed no modification on the corrosion character as compared to the nontreated reference.

\section{Acknowledgments}

This work is partially funded by FAPESP, to whom G.F. Gomes thanks a post-doctoral fellowship.

\section{References}

1. Capozucca R. Damage to reinforced concrete due to reinforcement corrosion. Construction and Building Materials. 1995; 9(5):295-303.

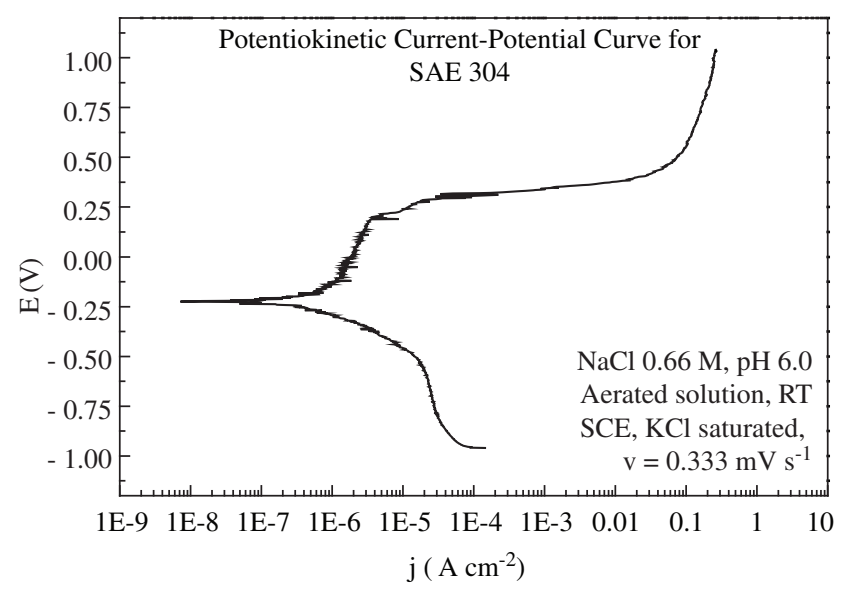

Figure 6. Corrosion profile of SAE 304 stainless steel.

2. Andrade C, Alonso C. On-site measurements of corrosion rate of reinforcements. Construction and Building Materials. 2001; 15(2-3): 141-145.

3. Agerskov H. Fatigue in steel structures under random loading. Journal of Constructional Steel Research. 2000; 53(3):283-305.

4. Anders A, Anders S, Brown I.G, Yu K.M. Increasing the retained dose by plasma immersion ion implantation and deposition. Nuclear Instruments and Methods in Physics Research Section B: Beam Interactions with Materials and Atoms. 1995; 102(1-4):132-135.

5. Wu ZC, Liu Y-L, Chen M-C. Passivation of copper films with magnesium doping using recoil ion implantation. Thin Solid Films. 2000; 358(12):180-186.

6. Ziegler JF, Biersack JP, Littmark U. The stopping and range of ions in matter, v.1. New York: Pergamon Press, 1985.

7. Saremi M. Mahallati E. A study on chloride-induced depassivation of mild steel in simulated concrete pore solution. Cement and Concrete Research. 2002; 32(12):1915-1921. 